\title{
Fe and Pt carbon nanotubes for the electrocatalytic conversion of carbon dioxide to oxygenates
}

\author{
M. Gangeri ${ }^{\text {a }}$, S. Perathoner ${ }^{\mathrm{a}, *}$, S. Caudo $^{\mathrm{a}}$, G. Centi $^{\mathrm{a}}$, J. Amadou ${ }^{\mathrm{b}}$, D. Bégin ${ }^{\mathrm{b}}$, \\ C. Pham-Huu ${ }^{\text {b }}$, M.J. Ledoux ${ }^{\text {b }}$, J.-P. Tessonnier ${ }^{c}$, D.S. Su ${ }^{\text {c }}$, R. Schlögl
}

a Dept. of Industrial Chemistry and Materials Engineering, University of Messina, Salita Sperone 31, Messina, Italy b Lab. Des Matériaux, Surface at Procédés pour la Catalyse, CNRS \& ULP, Strasbourg, France

${ }^{c}$ Fritz Haber Institut der M.P.G., Berlin, Germany

* Corresponding author: e-mail perathon@unime.it, Tel.: +39 0906765609; fax: +39 090391518.

Published Online: 19 December 2008; published 15 May 2009

\begin{abstract}
Using Pt/CNT or Fe/CNT electrocatalysts it is possible to convert carbon dioxide to liquid fuels, particularly isopropanol. Fe/CNT shows a better behavior than Pt/CNT, although a faster deactivation. The main reason of deactivation is cross-over of the electrolyte, particularly of $\mathrm{K}$ ions. They react with iron particles and cause their dissolution and migration. In the case of Pt/CNT there is no, or minor, dissolution of metal, but potassium covers the Pt particles and/or induce deactivation. It is shown, however, that the electrolyte was necessary to simulate the half-cell of the full photoelectrocatalytic device, while in the latter no electrolyte is needed, being the protons and electrons produced by water splitting. The elimination of the electrolyte probably could eliminate or significantly reduce a main cause determining the observed fast deactivation.
\end{abstract}

Keywords: Carbon dioxide, Electrocatalysis, Pt/CNT, Fe/CNT, $\mathrm{CO}_{2}$ conversion to isopropanol

\section{Introduction}

The global levels of atmospheric carbon dioxide, the primary driver of global climate change, increased by $0.6 \%$, boosting the global concentration to nearly 385 parts per million (ppm) in 2007 with respect to pre-industrial carbon dioxide levels of around $280 \mathrm{ppm}$ until 1850. The amount of $\mathrm{CO}_{2}$ emitted in human activities is estimated at about 26 Gtons per year that represents about $4 \%$ excess with respect to the yearly $\mathrm{CO}_{2}$-flow in the natural carbon cycle. The Intergovernmental Panel on Climate Change [1] indicated that with respect to 23.7 billion metric tons of annual global $\mathrm{CO}_{2}$ emissions caused by human activities (primarily the burning of fossil fuels) in 2005, the global chemical industry used approximately 115 million metric tons of carbon dioxide as a feedstock in a variety of synthetic processes. On the other hand, recycling $\mathrm{CO}_{2}$ as alternative to storage is a necessary component to close the carbon balance and stabilize troposphere level of $\mathrm{CO}_{2}$. While storage is an additional cost, $\mathrm{CO}_{2}$ recycle offers the possibility to make valuable products [2]. In addition, the carbon sequestration and storage (CSS) option requires suitable storage sites which are often far from the sources of $\mathrm{CO}_{2}$ emissions, with thus significant transport costs and additional $\mathrm{CO} 2$ emissions due to transport itself. $\mathrm{CO}_{2}$ recycle to chemicals and fuels is thus both an economic and environmental valuable option. Although still significant margins to increase the share of $\mathrm{CO}_{2}$ recycle for the production of chemicals exists, the volume of $\mathrm{CO}_{2}$ which can be converted to chemicals is estimated to not increase from the actual about $0.5 \%$ to over $1-2 \%$. Therefore, a larger contribution to the reduction of $\mathrm{CO}_{2}$ emissions could derive only by converting $\mathrm{CO}_{2}$ back to fuels [3].

There are several possibilities to convert carbon dioxide to fuels, the main of which are by reaction with (i) $\mathrm{H}_{2}$, for example reverse water gas shift coupled with methanol synthesis, hydrogenation to light alkanes or alkenes, or hydrogenation to other oxygenated (dimethyl ether, ethanol, formic acid), or (ii) hydrocarbons (dry, mixed or trireforming of methane; oxidative dehydrogenation). Other 
possibilities include biological processes (particularly with algae), microwave and plasma processes and photo- and electro- chemical/catalytic conversion of $\mathrm{CO}_{2}$ [4]. In perspective, the latter is the preferable solution, because uses a renewable source of energy (solar light) to convert back carbon dioxide to fuels, particularly when liquid hydrocarbons or oxygenated could be produced. Note, that liquid fuels are and will remain the preferable way to store energy in a form easy stackable and transportable. In addition, the possibility to convert $\mathrm{CO}_{2}$ to liquid fuels will preserve the large investments made in infrastructure for distributing them.

For this reason, the recent report "Catalysis for Energy" of US DoE [5] indicated the catalytic conversion of carbon dioxide into liquid fuels using solar and electrical energy, to enable the carbon in carbon dioxide to be recycled into fuels, as one of the three grand challenges for future research, but evidencing that the underlying science is far from sufficient for a design of efficient catalysts and economical processes.

We proposed a novel concept based on a gas-phase photoelectrocatalytic device [6,7], different from the conventional liquid phase photoelectrochemical (PEC) approach, based on liquid phase operations. In this device, one side (photocatalytic anode) is composed from a nanostructured $\mathrm{TiO}_{2}$-based thin film [8], where gaseous water is splitted using solar light to produce $\mathrm{O}_{2}$, protons and electrons. On the electrocatalytic anode side, based on novel nanostructured carbon-based electrodes, $\mathrm{CO}_{2}$ in gas phase is converted using protons and electrons coming from the photo- catalytic side and passing through a Nafion ${ }^{\circledR}$ membrane and a wire respectively.

The key aspect is the electrocatalyst. Various reviews have discussed the electrochemical reduction of carbon dioxide recently [9-11]. Electron conversion efficiencies of higher than $50 \%$ can be obtained, but at the expense of high overpotentials $(\sim 1.5 \mathrm{~V})$. In only a few studies methane or methanol have been the primary products of the reduction; the overall yields are low in the absence of high overpotentials and the electrode surface is susceptible to poisoning.

However, all these studies have been made in solution using traditional-type of electrodes. Using instead a gas-phase approach and nanocarbon-based electrocatalysts, e.g. similar to those used in PEM fuel cells, we showed that it is possible to form long-chain hydrocarbons at room temperature [12,13], although with low productivities.

We reported new results here showing that at higher temperatures $\left(60{ }^{\circ} \mathrm{C}\right)$ much larger productivities are possible, with the formation in particular of $\mathrm{C} 3$ oxygenated (acetone or isopropanol, depending on the electrocatalyst). This is the first time in which the possibility of synthesis of isopropanol from $\mathrm{CO}_{2}$, a 18 electron reduction, is reported. The differences between electrocatalysts based on noble or non-noble metals supported on carbon nanotubes are also analyzed.

\section{Experimental}

Commercial multiwalled carbon nanotubes (CNT) from Applied Science Inc. were used as starting materials after post-treatment in inert gas at $700{ }^{\circ} \mathrm{C}$. This treatment removes the amorphous carbon present on the outer surface and reduces the number of structural defects, thus increasing the graphitic character of the CNT. After this heat treatment, the samples are treated in nitric acid under reflux $\left(\mathrm{HNO}_{3} 65 \%\right)$ at $100{ }^{\circ} \mathrm{C}$ for $10 \mathrm{~h}$ to create oxygen functional groups on the surface of CNT, which are necessary to better anchor the metal particles. Then, CNT were impregnated with $10 \mathrm{wt} \% \mathrm{Fe}$ or $\mathrm{Pt}$ using as precursors $\mathrm{Fe}\left(\mathrm{NO}_{3}\right)_{3}$ $\square 9 \mathrm{H}_{2} \mathrm{O}$ or $\mathrm{H}_{2} \mathrm{PtCl}_{6}$. After drying at room temperature for 24 $\mathrm{h}$, the samples were calcined for $2 \mathrm{~h}$ at $350{ }^{\circ} \mathrm{C}$ and finally reduced under $\mathrm{H}_{2}$ at $400{ }^{\circ} \mathrm{C}$ for $2 \mathrm{~h}$.

The electrodes were prepared by first preparing a suspension of $\mathrm{Fe} / \mathrm{CNT}$ or Pt/CNT in ethanol and then depositing the suspension on carbon cloth (CC). After drying, the working electrode is assembled by hot-pressing joining the $\mathrm{CC}$ on a Nafion ${ }^{\circledR}$ membrane at $80 \mathrm{~atm}$ and $130{ }^{\circ} \mathrm{C}$ for $90 \mathrm{~s}$. The metal loading was about $0.5 \mathrm{mg} / \mathrm{cm}^{2}$. The active phase is located between the gas diffusion layer at direct contact with $\mathrm{CO}_{2}$ in the gas phase and the Nafion 1 membrane layer.

The samples were characterized by Zeta potential measurement, using a Malvern Instruments Zetasizer Nano equipped with the MPT-2 Autotitrator, to analyze the functionalization with acidic O-containing groups after oxidation with nitric acid, TG experiments in inert gas, SEM (scanning electron microscopy) and TEM (transmission electron microscopy).

The electrocatalytic tests of $\mathrm{CO}_{2}$ reduction were carried out in a semi-half continuous mode cell at $60^{\circ} \mathrm{C}$. The working electrode operates in contact with the gas phase $\mathrm{CO}_{2}$ flux, the protons (provided by an electrolyte which diffuse to the catalyst through a Nafion ${ }^{\mathbb{B}}$ membrane) and the electrons (provided by applying a constant current of 20 $\mathrm{mA}$ between a Pt ring in contact with the working electrode and a counter electrode in contact with the electrolyte on the other side of the cell). The geometrical area of the electrode in contact with the gas phase is ca. $1 \mathrm{~cm}^{2}$. The electrolyte is a purified $0.5 \mathrm{M}$ solution of $\mathrm{KHCO}_{3}$ in distilled water. The counter electrode (platinum wire) and the reference electrode (saturated $\mathrm{Ag} / \mathrm{AgCl}$ electrode) are located in this electrolyte which is separated from the working electrode by a Nafion ${ }^{\circledR} 117$ membrane. A potentiostat/galvanostat (Amel mod. 2049A) is used to supply the current and monitor the potential between the working and counter/reference electrodes.

The procedure for reactivity tests was the following: after purification of the system in $\mathrm{N}_{2}$ for $1 \mathrm{~h}$ and $\mathrm{CO}_{2}$ preadsorption for saturation of the system (typically $30 \mathrm{~min}$ ), $\mathrm{CO}_{2}$ $(20 \mathrm{ml} / \mathrm{min}$ ) is fed for $2 \mathrm{~h}$. Experiments were conducted galvanostatically changing, after $1 \mathrm{~h}$, the polarity of current from $-20 \mathrm{~mA}$ to $+20 \mathrm{~mA}$ to improve desorption of the products from the working electrode and trapping the reaction products in a cold trap $\left(-30^{\circ} \mathrm{C}\right)$. Analysis of the reac 

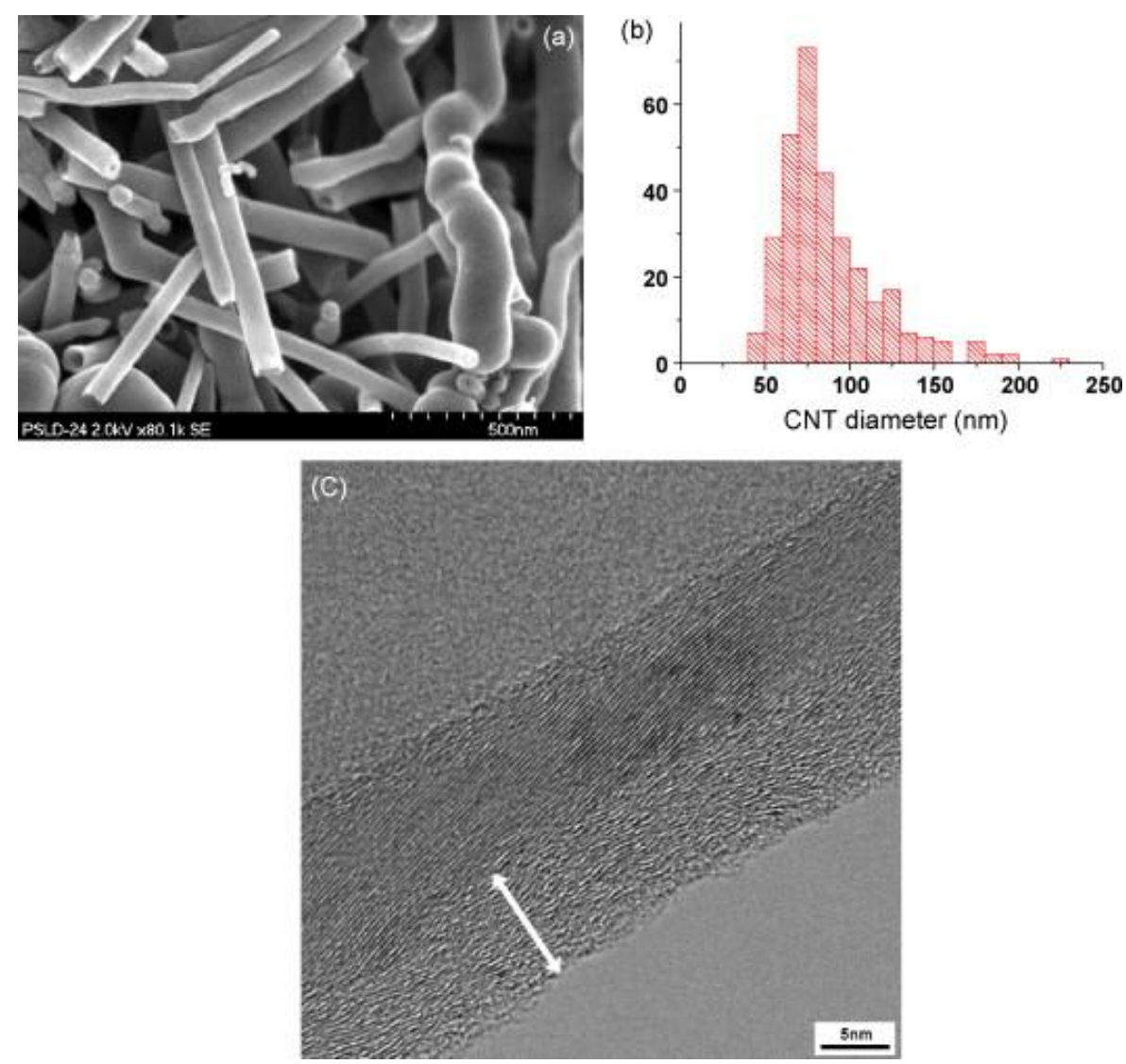

Fig. 1: (a) SEM image of the pristine CNT from Applied Science; (b) distribution of external diameter; (c) TEM image of the pristine CNT thermally treated at $700^{\circ} \mathrm{C}$.

tion products was made by a gas-chromatograph (GC) equipped with a FID detector and a gas-mass GC (MSGC) apparatus. Blank initial experiments were made to check whether in the absence of the electrocatalyst layer, of $\mathrm{CO} 2$ in the gas phase or of a voltage applied across the cell, the products of reaction were detected. A negative response was obtained in all cases.

\section{Results and discussion}

\subsection{Characterization of the electrocatalysts}

The commercial (Applied Science) pristine CNT used as support for $\mathrm{Pt}$ and $\mathrm{Fe}$ has a relatively broad size distribution, with an outer diameter of $88 \pm 30 \mathrm{~nm}$. The SEM image (Fig. 1a) shows that the samples contain minimal amounts of carbon impurities. However, TEM image (Fig. 1c) indicates that only the inner surface of CNT shows an effective CNT structure with the graphitic layers oriented along the axial direction, while on the external surface a disordered carbon structure is present with a thickness of around 5-6 nm.

The characterization after the treatment with nitric acid shows the presence of oxygen functional groups. It was reported in theliterature that most of the oxygen functional groups existing on carbon can be removed from the surface by heating in inert gas between $200{ }^{\circ} \mathrm{C}$ and 1100 ${ }^{\circ} \mathrm{C}$. Thus, it is possible to quantify the amount of oxygen groups existing on the surface of the CNTs before impregnation with metal precursors by thermogravimetric analysis. It was found that the mass loss in the $25-700{ }^{\circ} \mathrm{C}$ temperature range was $5.2 \%$, while $5.3 \%$ in the $700-1100$ ${ }^{\circ} \mathrm{C}$ temperature range. The first loss could be attributed to carboxylic acid and carboxylic anhydride, while the higher temperature loss could be attributed to lactonic, quinolic and phenolic groups [14-16]. If after the treatment with nitric acid, the sample is treated in an inert atmosphere up to $800{ }^{\circ} \mathrm{C}$, the weight loss in the low temperature range decreases to zero, while only a minor change is present in the higher temperature region $(5.2 \%$ loss $)$. If, on the contrary, the pristine $\mathrm{CNT}$ is treated at $1500{ }^{\circ} \mathrm{C}$ in an inert atmosphere prior the treatment with nitric acid, the low temperature loss is also nearly zero, while the higher temperature loss $4.2 \mathrm{wt} \%$. This treatment at $1500{ }^{\circ} \mathrm{C}$ do not change the mean diameter of the CNT, but induces a graphitization of the external surface of CNT with the elimination of the highly disorganized carbon present on the external surface pristine CNT, as evidenced by TEM images. We may conclude that the carboxylic acid and carboxylic anhydride groups (low temperature loss) formed by treatment with nitric acid are associated mainly to the disordered carbon present on the outer surface of the commercial CNT used in these tests, while the other oxygenated 


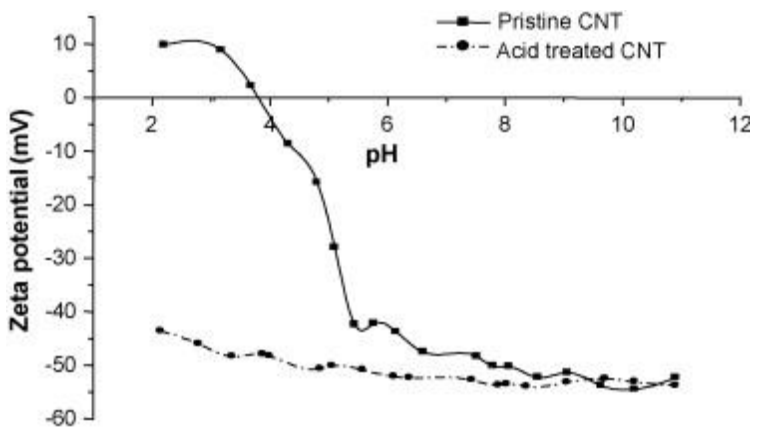

Fig. 2: Zeta potential measurements as a function of the $\mathrm{pH}$ of the solution for pristine and nitric acid treated CNT.

groups thermally resistant to the treatment at $700{ }^{\circ} \mathrm{C}$ (lactonic, quinolic and phenolic groups) are instead present mainly in the internal walls of the CNT.

Zeta potential measurements of CNT (Fig. 2), realized adding $5 \mathrm{mg}$ of CNT to $50 \mathrm{ml}$ of a $\mathrm{NaClO}_{4}$ solution $\left(10^{-3} \mathrm{M}\right)$, show that after the treatment with nitric acid a drastic lowering of the surface charge is induced, particularly in the $\mathrm{pH}$ range below about 5. It is reasonable that this is associated to the stronger acid sites formed by treatment with nitric acid, e.g. the carboxylic acid and carboxylic anhydride groups present on the highly disorganized carbon present on the outer surface, because the weaker lactonic, quinolic and phenolic groups could be not responsible for this lowering of zeta potential.

The deposition of the metal was made by incipient wetness impregnation in acidic conditions ( $\mathrm{pH} \sim 2$ ), using a solution of water $(80 \%)$ and ethanol $(20 \%)$ to solve the metal salts. There are thus two phenomena which occurs at the same time. For nitric acid treated CNT, as shown in Fig. 2 , the surface charge at $\mathrm{pH} \sim 2$ is negative, so there is an ionic interaction of the acidic sites on the external surface of CNT with the metal cation in solution to form highly dispersed ions and then well dispersed metal particles. The second is the filling of the CNT by impregnating solution thanks to ethanol that allows to increase the filling by increasing the wetting of the inner channel of the carbon nanotubes owing to its hydrophilic $(-\mathrm{OH})$ and hydrophobic $\left(\mathrm{CH}_{3}-\mathrm{CH}_{2}-\right)$ duality.

In agreement, TEM images of the samples show the presence of a dual type of metal particles. Fig. 3a shows a TEM image of a Fe/ CNT sample which indicates the presence of small nanoparticles of 4-6 nm size and larger particles, slightly elongated, with dimensions about $30 \mathrm{~nm} \times$ $45 \mathrm{~nm}$. Tomography (3D-TEM), was used to analyze the location of these particles, e.g. if inside or outside the nanotube.On a selected area, a series of 16 images at different tilt angle (from $-35^{\circ}$ to $+40^{\circ}$ by steps of $5^{\circ}$ ) were recorded, and then assembled to make a video. This analysis showed clearly that the biggest nano-particles were located only inside the nanotube, whereas the smallest one decorates the outer surface. This is well consistent with above indications.
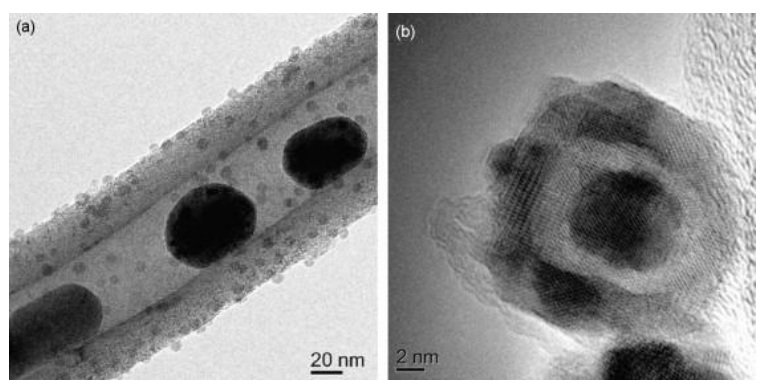

Fig. 3: (a) TEM and (b) HRTEM images of Fe/CNT electrocatalyst.

High-resolution TEM images were also recorded in order to identify the iron phase (Fig. 3b). In most cases, the metal particles are too thick to image the central region. The images acquired at the edges seem to indicate a coreshell structure. A final conclusion concerning the nature of the Fe phases cannot be reached due to the overlap of the lattice fringes of these phases. However, none of the measured lattice spacing corresponds to metallic iron and analysis of images acquired on 10-15 nm nanoparticles is consistent with the presence of $\mathrm{Fe}_{3} \mathrm{O}_{4}$. Elemental mapping, performed in STEM mode on bigger Fe particles (Fig. 4), clearly confirm that the bigger particles are also made of iron oxide.

In the case of the Pt/CNT (Fig. 5a), the nanoparticles typically present a diameter of 1 to $2.5 \mathrm{~nm}$, with some bigger particles of up to $15 \mathrm{~nm}$, also located internally to CNT. Lattice spacings of $1.93 \AA$ and $2.23 \AA$ were measured on the biggest nanoparticles imaged by HRTEM (Fig. 5b), which correspond to Pt (200) and Pt (111), respectively. The presence of big particles internally to nanotubes both for Fe/CNT and for Pt/CNT could be explained by a saturation of the metal concentration inside the tubes and so the creation of big nanoparticles.

\subsection{Electrocatalytic conversion of $\mathrm{CO}_{2}$ using $\mathrm{Fe}$ and Pt nanoparticles supported on CNT}

Fig. 6 compares the performance of $\mathrm{Fe} / \mathrm{CNT}$ and $\mathrm{Pt} / \mathrm{CNT}$ electrocatalysts, each containing the same loading of metal (about $10 \mathrm{wt} \%$ with respect to CNT, e.g. about 0.5 $\mathrm{mg} / \mathrm{cm}^{2}$ electrode), in the $\mathrm{CO}_{2}$ gas phase electrocatalytic reduction. The experiments were performed at $60^{\circ} \mathrm{C}$, since our previous results [13] showed low productivities at room temperature. Modulations in the current were used to improve the desorption of products. A $1 \mathrm{~cm}^{2}$ electrode was used and reaction time was $2 \mathrm{~h}(1 \mathrm{~h}$ of reduction at -20 $\mathrm{mA}$ and $1 \mathrm{~h}$ of desorption at $+20 \mathrm{~mA}$ ). In general, the iron catalyst shows a higher productivity in comparison with the Pt catalyst. The main product of reaction is isopropanol, plus minor amounts of other lighter alcohols or acetone. Hydrocarbons from $\mathrm{C} 3$ up to $\mathrm{C} 9$ are also detected, but in an amount one to two order of magnitude lower. Although the type of products are similar for the two electro- catalysts, a different distribution of products is observed. 
Bright field

(a)

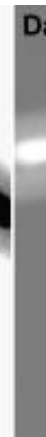

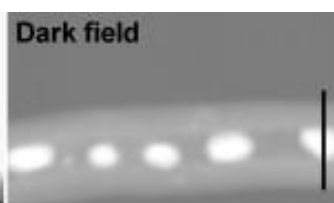

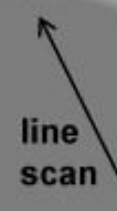

(b)

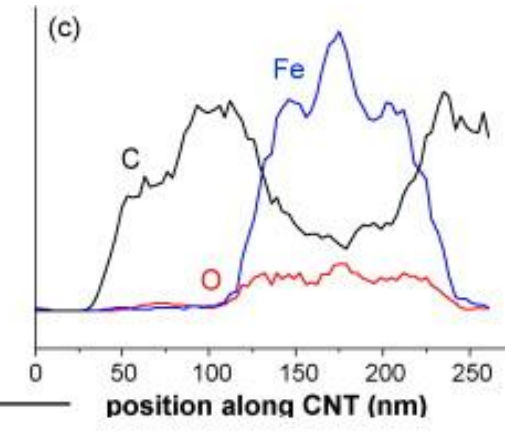

Fig. 4: (a) Bright field and (b) dark field images of a CNT filled with metal nanoparticles. The black line on the dark field image indicates the path of the line scan shown in (c) image.
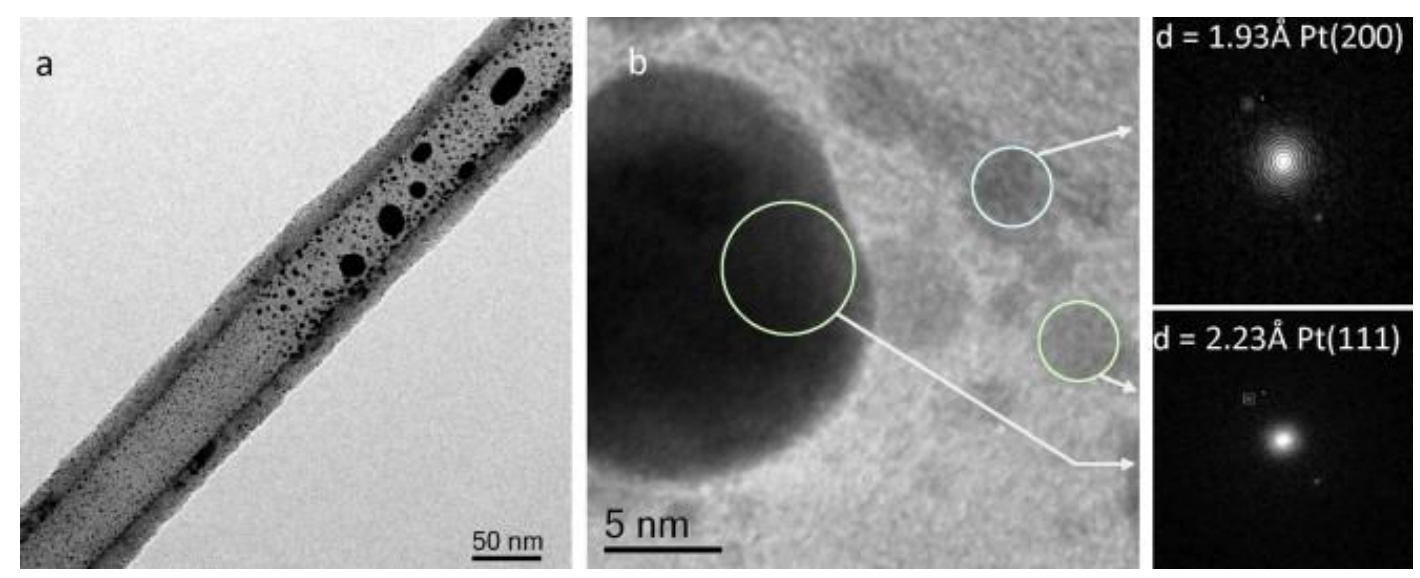

Fig. 5: (a) TEM image of the Pt/CNT electrocatalyst. (b) HRTEM images of the orientation of Pt planes.
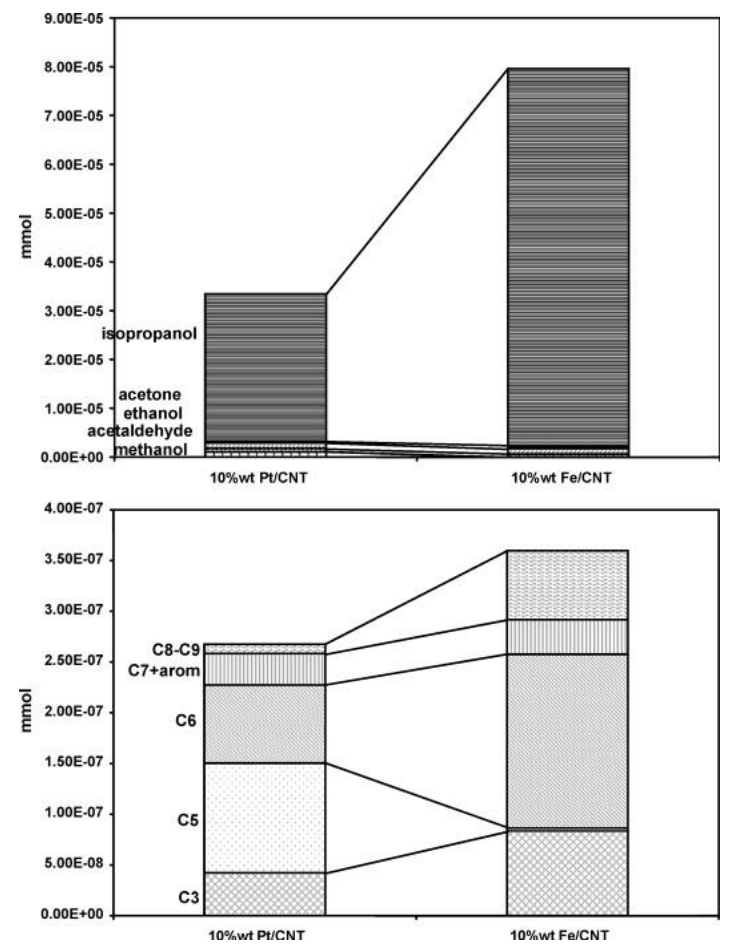

Fig. 6: Products distribution after $2 \mathrm{~h}$ of reaction in $\mathrm{CO}_{2}$ electrocatalytic reduction on $\mathrm{Pt} / \mathrm{CNT}$ and $\mathrm{Fe} / \mathrm{CNT}$.
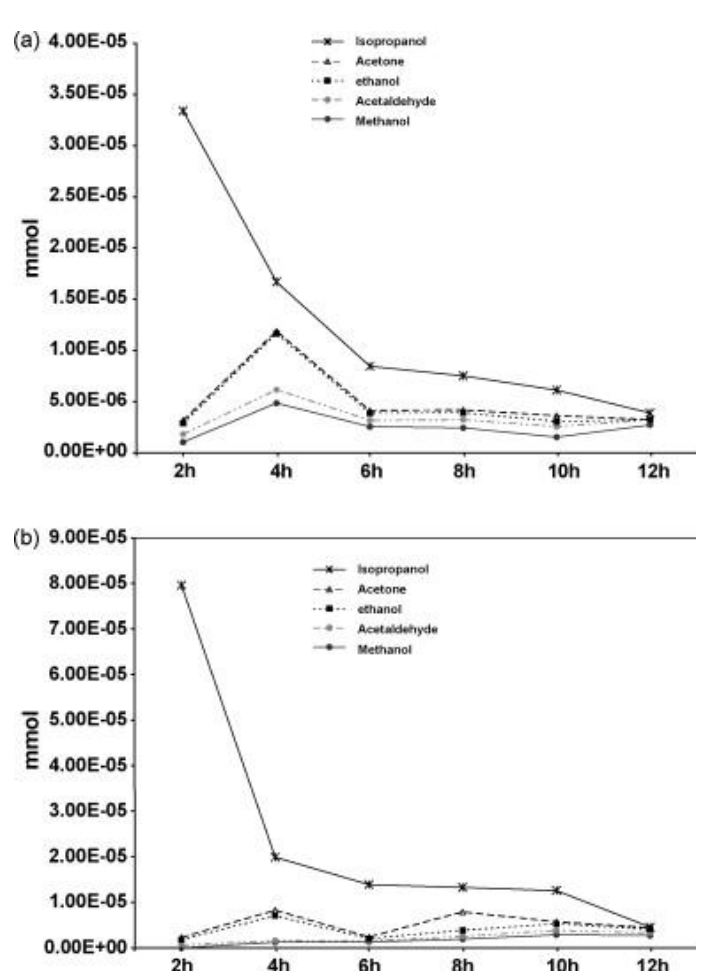

Fig. 7: Behavior during consecutive reaction cycles: Pt/CNT (a) and $\mathrm{Fe} / \mathrm{CNT}$ (b). 

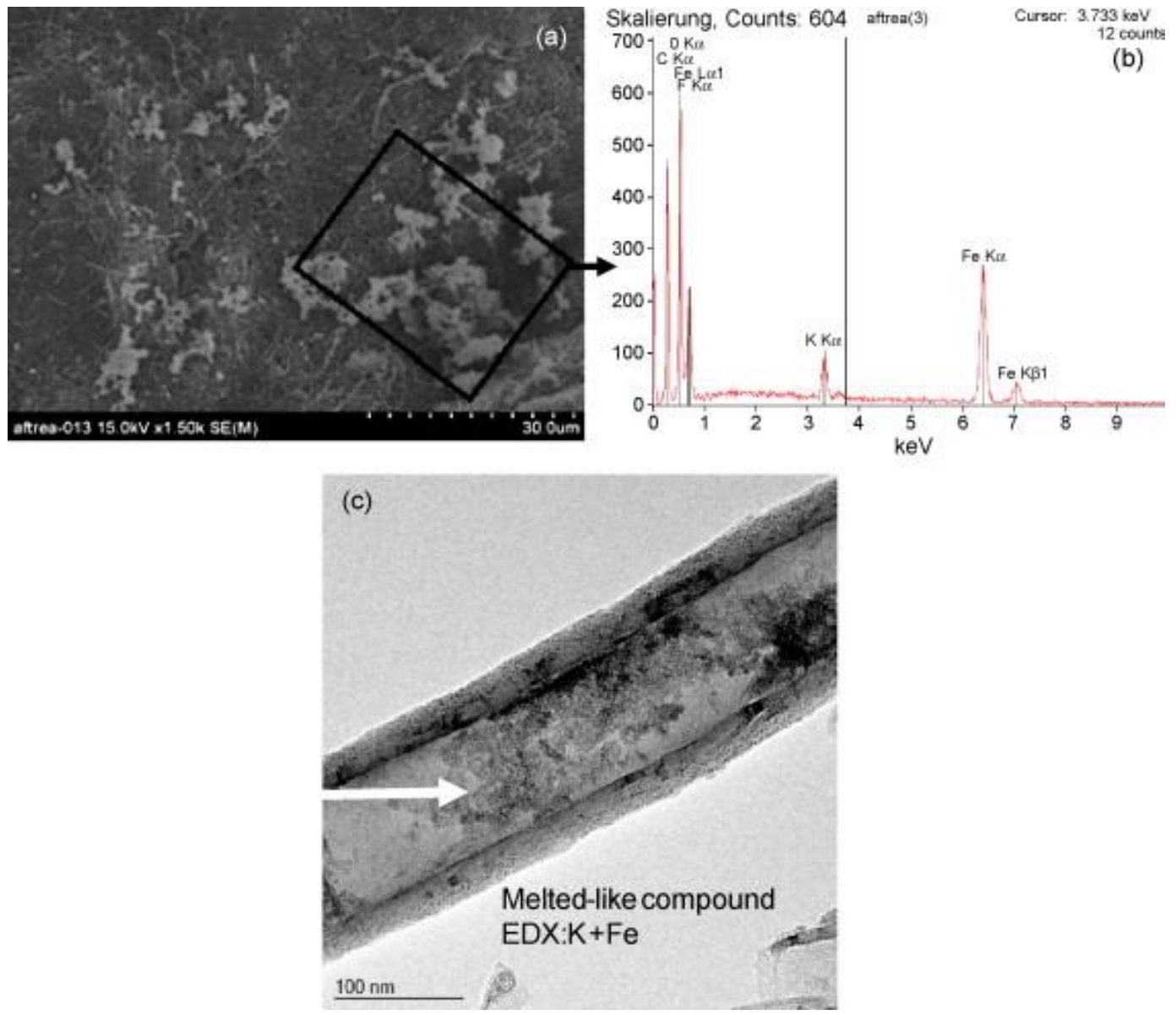

Fig. 8: (a) SEM image of Fe/CNT electrocatalyst after reaction; (b) EDX analysis of the part of images indicated in (a); (c) TEM image of $\mathrm{Fe} / \mathrm{CNT}$ catalyst after 3 cycles of reaction.

The stability of the electrocatalysts in consecutive reaction cycles was analyzed, founding that the productivity of both $\mathrm{Fe}$ and $\mathrm{Pt}$ catalysts decreases during consecutives tests (each of $2 \mathrm{~h}$ ). However, Pt/CNT shows a three times slower deactivation rate in comparison with Fe/CNT (Fig. $7 \mathrm{a}$ and $\mathrm{b}$ ). Moreover, it was observed that, for higher reaction times, the Pt catalyst is more selective towards $\mathrm{C} 1-\mathrm{C} 2$ oxygenate products (in particular, methanol) than the $\mathrm{Fe}$ catalyst.

\subsection{Characterization of the electrocatalysts after the electroreduction of $\mathrm{CO}_{2}$}

The electrocatalysts after the tests in $\mathrm{CO}_{2}$ reduction were analyzed by SEM and TEM, in order to identify the motivations of the catalyst deactivation.

In the case of Fe/CNT, SEM images showed a progressive decrease of iron, proportional to the number of cycles of reaction. On the contrary, in the case of $\mathrm{Pt} / \mathrm{CNT}$, the number of Pt nanoparticles was only slightly lower than in the initial sample, thus indicating a reduced leaching.

SEM-EDAX images also indicate that $\mathrm{K}$ was present in the CNT, while not in the initial sample. Fig. 8 evidences at the interface between $\mathrm{Fe} / \mathrm{CNT}$ and the Nafion ${ }^{\circledR}$ the presence of aggregates which characterization by EDX (marked area in Fig. 8a) indicates the presence of $\mathrm{Fe}$ and $\mathrm{K}$. This shows that cross-over of the electrolyte occurs and potassium reacts with Fe inducing the dissolution of iron particles. This hypothesis is further supported by SEM images at higher magnification. The CNTs appeared to be glued together by a material that looks bright in BSE mode, as elements heavier than $\mathrm{C}$. Moreover, the $\mathrm{FeO}_{\mathrm{x}}$ nanoparticles that were clearly seen in and on the CNTs in the case of the fresh catalyst cannot be found anymore. High-resolution images (Fig. 8c) show that many tubes are filled with an amorphous, melted-like material and EDX analysis on selected areas indicated that this material is again composed of $\mathrm{Fe}$ and $\mathrm{K}$.

We may conclude that, due to cross-over, the $\mathrm{KHCO}_{3}$ solution passes through the Nafion1 membrane and favors the Fe leaching. The $\mathrm{Fe}$ is progressively leached and either migrates towards the solution or remains inside the nanotubes as amorphous mixture of $\mathrm{Fe}$ and $\mathrm{K}$.

In the case of the $\mathrm{Pt} / \mathrm{CNT}$, crystals containing potassium could be seen on the surface of the catalyst and these crystals cover a fraction of the surface, but no main migration of Pt particles could be observed different from $\mathrm{Fe} / \mathrm{CNT}$. The deactivation observed during the successive 
cycles of reaction could be linked to metal particle encapsulation in K crystals.

The cross-over of part of the electrolyte is thus one of the main reasons for the observed deactivation. We should note, however, that the electrolyte was used in these experiments, because only half-cell of the full photoelectrocatalytic device described in the introduction was used and it was thus necessary to use an electrolyte to supply the protons through the Nafion1 membrane and close the circuit of the cell. In the full cell, no electrolyte is present, because the protons are generated by water splitting at the photoanode. Although the need to further develop the photocathode do not allow still to use the full cell, it may be expect that the elimination of the cross-over could eliminate a main reason of deactivation of the electrocatalyst and thus allows stable operations.

\section{Conclusions}

The results of this work evidence that using Pt/CNT or $\mathrm{Fe} / \mathrm{CNT}$ electrocatalysts it is possible to convert carbon dioxide to liquid fuels, particularly isopropanol. This is the first time, to our knowledge, that it is demonstrated that this difficult and challenging reaction (a 18th electron conversion) could be realized with reasonable productivities. $\mathrm{Fe} / \mathrm{CNT}$ show a better behavior that Pt/CNT, although a faster deactivation which, however, occurs in both cases after few cycles of reaction. Preliminary tests not reported here, however indicate that $\mathrm{Fe}-\mathrm{Co} / \mathrm{CNT}$ samples show an even more stable behavior.

The main reason of deactivation is due to cross-over of the electrolyte, particularly of $\mathrm{K}$ ions. They react with iron particles and cause their dissolution and migration. In the case of $\mathrm{Pt} / \mathrm{CNT}$ there is no, or minor, dissolution of the metal, but potassium covers the Pt particles and/or induce deactivation. It is shown, however, that the electrolyte was necessary to simulate half-cell of the full photoelectrocatalytic device, while in the latter no electrolyte is needed, being the protons and electrons produced by water splitting. The need to still improve the $\mathrm{TiO}_{2}$-based photoanode did not allowed to test the full device, but the elimination of the electrolyte probably will eliminate or significantly reduce a main cause determining the observed fast deactivation.

\section{Acknowledgements}

The authors would like to acknowledge the European Commission for its financial support in the NEST program "ELCAT" and Dr. Daniele Cosio for its precious technical assistance.

\section{References}

[1] B. Metz, O. Davidson, H. de Coninck, M. Loos, L. Meyer (Eds.), Carbon Dioxide Capture and Storage (IPCC Special Report), Cambridge University Press, UK, 2005.

[2] M. Aresta, A. Dibenedetto, Dalton Trans. 28 (2007) 2975.

[3] G. Centi, S. Perathoner, Carbon dioxide utilization for global sustainability, Stud. Surf. Sci. Catal. 153 (2004) 1.

[4] G. Centi, G. Cum, Conversion of carbon dioxide to fuels and chemicals, Direct Conversion of Methane, Ethane and Carbon Dioxide to Fuels and Chemicals, The Catalyst Group Pub, Spring House, PA, USA, in press (Chapter 4).

[5] A.T. Bell, B.C. Gates, D. Ray, Basic Research Needs: Catalysis for Energy, U.S. Department of Energy Pub, Washington, DC, 2007.

[6] G. Centi, S. Perathoner, Z. Rak, Stud. Surf. Sci. Catal. 145 (2003) 283.

[7] G. Centi, S. Perathoner, Z. Rak, Appl. Catal. B: Environ. 41 (2003) 143.

[8] S. Perathoner, R. Passalacqua, G. Centi, D.S. Su, G. Weinberg, R. Schlögl, Catal. Today 122 (2007) 3.

[9] J.-L. DuBois, Electrochemical reactions of carbon dioxide, Encycl. Electrochem. 7 (2006) 202.

[10] ] M. Gattrell, N. Gupta, A. Co, J. Electroanal. Chem. 594 (2006) 1.

[11] C. Oloman, H. Li, ChemSusChem 1 (2008) 385.

[12] G. Centi, S. Perathoner, G. Wine, M. Gangeri, Converting $\mathrm{CO} 2$ to fuel: a dream or a challenge? in: Preprints of Symposia-American Chemical Society, vol. 51, Division of Fuel Chemistry, (2006), p. 745.

[13] G. Centi, S. Perathoner, G. Wine, M. Gangeri, Green Chem. 9 (2007) 671.

[14] G.S. Szymaski, Z. Karpiski, S. Biniaka, A. Switkowski, Carbon 40 (2002) 2627.

[15] C. Moreno-Castilla, M.V. López-Ramón, F. Carrasco-Marín, Carbon 38 (2000) 1995.

[16] W. Shen, Z. Li, Y. Liu, Recent Patents Chem. Eng. 1 (2008) 27. 